\title{
Occupational Inequalities in Temporal Autonomy: A Multidimensional Perspective
}

\author{
Jeanne Ganault (CREST, OSC) \\ [Pre-print version]
}

\begin{abstract}
Tertiarization and intensification of work have brought about new forms of temporal autonomy, yet they are often reduced to having (or not) control over one's work hours or schedule. This has important implications on our understanding of how temporal autonomy relates to social inequalities. This paper thus intends to shed light on the multiple dimensions of temporal autonomy and to determine whether they are hierarchically distributed among the French wage-earner population. Using the 2010 French Time-Use survey, three dimensions of temporal autonomy are identified : control over work time is found to be hierarchically distributed; control over time off is industryspecific and less available to workers in education, health, personal services and manufacturing; and autonomy in work organization is more dependent on size of establishment and is gradually more prevalent as size decreases. These results contribute to better understand the extent to which social position shapes working conditions.
\end{abstract}

Inequality; Occupations; Organizations; Social position; Temporal autonomy.

\section{Introduction}

The employment relationship, as a by-product of industrialization, was historically inscribed in a temporal power dynamic in which employers exerted control over their employees' time (Thompson 1967). While this hierarchical determination of work time prevailed in an economy predominantly driven by the secondary sector, the tertiarization and diversification of activities brought about new forms of time control, or lack thereof. The extent to which these new, complexified forms of temporal autonomy challenge a hierarchical reading of positions within the labor market has yet to be explored.

The emergence of temporal "autonomy" as a major component of the employment relationship has been well documented (Boltanski and Chiapello 2005). While a few studies provide detailed accounts of how temporal autonomy interacts with social position within a particular occupation, organization or industry (Hodson 2001), whether temporal autonomy systematically reflects employees' social position is not so clear. This is mainly due to a restrictive definition of temporal autonomy in quantitative works, i.e. control over work hours, in light of the complexity and variety of time constraints workers might be subjected to. The rise of the service economy combined with stagnated productivity in manufacturing and intensification of work have created new rhythms at both ends of the social hierarchy: managers who get to 
choose their daily work hours and location might be unable to anticipate their schedule if their workload depends on external demand; delivery workers might also face high unpredictability, yet have no control over where to work and when to stop. By identifying three dimensions of temporal autonomy - i.e. control over work time, control over time off and autonomy in work organization -, this paper intends to clarify the link between one's social position and the nature and degree of their temporal autonomy. This could contribute to research on social inequalities in time use by investigating whether unequal social positions are reproduced and reflected in unequal degrees of temporal autonomy in all its dimensions.

In doing so, this research intends to raise a question often neglected within literature on temporal autonomy: discerning the hierarchical dimension from the activity-specific dimension of one's occupation and the context in which this activity is conducted. Although research on the determinants of temporal autonomy often draws a distinction between "occupational" factors (occupation or income) and "organizational" factors (industry, size of establishment), rarely does it clearly state their different implications in terms of social inequality. But changing occupation is both much more determined by and determinant of one's economic, cultural and social resources than changing establishment or industry.

By focusing on France, an industrialized country with an occupational classification scheme directly inscribed in economic, cultural and social hierarchical orders (Deauvieau et al. 2014), this research provides some new perspectives on the way occupations might shape work time. The implementation of the French 35-hour statutory work week, in 1998 and 2000, created a wide array of situations depending on the bargaining power of both the employer and the employee (Estrade and Ulrich, 2002), possibly strengthening the connection between social class and time-related working conditions (Fagan, 2001) and making it a relevant case study for exploring temporal autonomy's multiple dimensions.

Using data from the French 2010 Time-use Survey on 8086 respondents representative of the French employee population, this paper aims at identifying the different dimensions of temporal autonomy workers might now be faced with, and explaining their unequal distribution. The paper is organized as follows: first, I review the literature on temporal autonomy and identify three theoretical dimensions of temporal autonomy. I then present the data and how I operationalize temporal autonomy and test hypotheses on its distribution. Results are then presented and finally discussed.

\section{Theoretical Background}

\section{The rise of temporal autonomy}

Unlike duration and conditions of work time, temporal autonomy is a rather recent concern. In an economy driven by industrialized mass production, where manufacturing shifted from a familial affair to fragmented and automated activities in 
large-scale factories, work hours and work schedules were almost exclusively shaped by employers, justifying theories of time control rather than temporal autonomy (Thompson 1967). However, the hierarchical and "industrial" control employers had over their employees was gradually challenged in a "third spirit of capitalism" in which "autonomy" became an ideal increasingly advocated by management and a more prevalent job characteristic (Boltanski and Chiapello 2005). Direct supervision by hierarchy gave way to direct dependency to external demand and an erosion of standard and stable time frames in the growing service industry (Boulin et al. 2006). Yet it remained largely implemented in former leading sectors, creating a wide variety of time constraints overall (Boisard et al. 2003), and among wage-earners specifically, justifying the need for further conceptualization of temporal autonomy for that population.

Most of the literature on workers' temporal autonomy has focused on selfemployed workers, who should in theory dispose of their time freely yet in practice often do not (Sharma, 2014). Yet wage-earners still make up the very large majority of the working population today, and better understanding what types of constraints they are subjected to, or freedoms they benefit from, could not only help inform on their working conditions, but create a reference frame to study self-employed workers in similar situations, occupations or organizations as this employment status expands. This is all the more pressing in a context of destandardization and feminization of work which created unprecedented pressure on work hours and who gets to shape them, as women were no longer available to assume a role of full-time care-dealer (Reynolds 2014) and workers were unequally likely to be offered employee-oriented flexibility or subjected to employer-driven flexibility (Golden 2001; Drago et al. 2009; Glauber 2011; Lyness et al. 2012; McCrate 2012). Identifying dimensions of temporal autonomy thus becomes a challenging task and a gateway to understand its differentiated and unequal distribution.

\section{Social positions, occupations and organizations shaping temporal autonomy}

The relevance of objectifying employees' working conditions regarding time allocation lies in their relation to social inequalities. Previous work shows that workers who benefit from control over work hours occupy higher positions within the social gradient, such as managers and professionals (Lesnard 2008; Golden 2001; Lyness et al. 2012). As occupations are closely intertwined with social class (Conk, 1978), and even more so in the French socio-professional categories ("PCS") deliberately built on class-specific characteristics and still acting as class signals (Deauvieau et al. 2014), the correlations between occupations and the ability to choose work hours might be read as a social class effect: as one's position in the social hierarchy, in which unskilled labor would be at the bottom and senior managers at the top, would increase, so would their freedom in work time allocation (Bourdieu 1979, Sharma 2014).

However, occupations also refer to specific activities, associated with specific time frames and time constraints, and conducted within a specific organization. As 
such, they might have a proper and direct effect on temporal autonomy, independently of the social status they convey (Lesnard 2008). Workers in the same occupation might have varying leeway in controlling their schedule depending on the size of their establishment (Pailhé and Solaz 2009), as smaller organizations might facilitate negotiations between employees and their hierarchy. Work context could also offset the effect of social position by either imposing similar forms of constraints to socially differentiated occupations, in the health sector for instance, or by alleviating them, through generalized flexible work arrangements. Yet, while doctors and nurses do share unpredictability in their work time, doctors can adjust to it much more than nurses can (Clawson and Gerstel 2014). Disentangling the effects of social position from work context therefore requires identifying the various dimensions temporal autonomy might entail and how they intertwine.

This example also highlights the role of gender in determining the type and degree of temporal autonomy workers might get, as doctors and nurses are highly segregated occupations (Clawson and Gerstel 2014) and gender is found to be significant in determining control over work time (Fagan 2001; Glauber 2011; Lyness et al. 2012). Although female-dominated occupations do not systematically benefit from greater access to work-hours flexibility, unlike "integrated" occupations in the labor market (Glauber 2011), women can also be overrepresented in occupations facilitating work-life reconciliation - either through selection (Wiswall and Zafar 2018) or gendered policy implementation (McCrate 2012). However, exploring gender inequality in temporal autonomy would entail a much bigger discussion which goes beyond the scope of this article and could be the subject of future research.

\section{The case of France}

The French context offers interesting specificities to improve our understanding of temporal autonomy. Most literature on temporal autonomy has focused on the US or the UK, yet the multidimensionality of temporal autonomy is not always reflected in their data. As a way to follow up on consequential working time reforms, French data allows for a wider exploration of both what autonomy entails and what its connection to social position is. In 1998 and 2000, legislations setting a 35-hour statutory workweek for all wage-earners virtually limited overwork and temporal disparities among workers. However, the reform was in fact not implemented similarly for all wage-earners, depending on their involvement in negotiations. While managers were able to choose to work longer weeks and cumulate more vacation days, workers in subordinate occupations were exposed to the discretion of their employers (Lehndorff, 2014) and more imposed flexibility (Estrade and Ulrich 2002), creating "unilateral configurations" of working-time symptomatic of liberal economies (Berg et al., 2014). Results on France could thus be relevant for other industrialized countries. 


\section{Forms of temporal autonomy}

A few studies have identified different occupational time frames, ranging from the duration of work to its "tempo" or "intensity" (Fagan 2001; Boisard et al. 2003; Anttila et al. 2015), featuring "autonomy" as one straightforward component which workers could either have or not. Some approached autonomy through the lens of work-life policies (Pailhé and Solaz 2009; Kerkhofs et al. 2008), without taking into account differentiation within establishments (Sweet et al. 2014) or how it relates to workers' social position. This section identifies three aspects of temporal autonomy and their relation to workers' social position and work context.

\section{Control over work time}

Temporal autonomy has often been conflated with control over work hours (Gerstel and Clawson 2018), which could be seen as the most prevalent time constraint (or freedom) employees face at work. It can manifest in two ways: control over when to work during the day, and control over the number of hours worked (Lyness et al. 2012). Typically, imposed part-time work or zero-hour contracts are predominantly offered to low-status, precarious workers (Kalleberg 2011), who are also less likely to benefit from "flexitime" policies allowing them to choose when to start and end their workday (Sweet et al. 2014). On the other hand, workers who are offered these policies do not necessarily make use of them (Eaton 2003; Lambert et al. 2008), if they feel like using them might jeopardize their career advancement (Williams et al. 2013) or come at the cost of work intensification (Kelliher and Anderson 2010).

Work hours are also strongly determined by external, "demand" constraints (Boisard et al. 2003) which can lead to unpredictable schedules. While "normal unpredictability" is something high status workers (such as doctors, managers working on "projects" or on "sites") can experience, unpredictability combined with lack of control is typical of low status positions, such as assistant nurses (Clawson and Gerstel 2014) or retail workers (Henly and Lambert 2014). These unqualified white-collar workers are subjected to "temporal availability" (Boulin et al. 2006). In care work for instance, schedules can be prolonged, delayed or changed by that of the person who is cared for (Sharma 2014). The overall lack of control over the number of hours worked, when they are worked and how predictable they are for low-qualification and lowstatus occupations thus suggests control over work time is mostly driven by the hierarchical dimension of occupations.

H1a: Control over work time is a social gradient: higher-status occupations have gradually more control over work time than lower-status occupations, all other things being equal.

H1b: Control over work time is explained by social position more so than by work context.

\section{Control over time off}

Beyond scheduling the beginning and end of workdays, temporal autonomy can also consist in arranging daily and/or long-term breaks. Freedom in taking time off on a 
daily basis (taking breaks, leaving work in case of an emergency) has been historically unavailable to manual workers. Assembly-line workers lack control at work, as they have to clock-in and clock-out and can neither choose when to take a lunch nor a bathroom break (Linhart 1981; Linder and Nygaard 1998). While this might be symptomatic of a subordinate position within the social ladder, it is also typical of "automatic constraints" in manufacturing industries (Boisard et al. 2003). Industries facing other types of rigid time constraints, either relying on non-stop availability like in health or personal services, or on specifically scheduled workers like in education, are less likely to enable workers to stop working without notice or schedule days off without arranging for a replacement (Pailhé and Solaz 2009 ; Kerkhofs et al. 2008).

In that sense, working in a specific industry could be more predictive of one's ability to schedule breaks, impromptu leaves or vacations than the status their occupation conveys, as it is more predictive of work intensity and tempo (Boisard et al. 2003; Anttila et al. 2015). Size of the establishment is also found to be amongst the most determining factors of both "day-to-day" and "life-course" flexibility (Kerkhofs et al. 2008), yet results on the effect of size vary with the type of flexibility measure (Sweet et al. 2014). While freedom in scheduling days off is not included in previous studies, the ability to take time off on a daily basis is less prevalent in bigger establishments (Pailhé and Solaz 2009).

H2a: Control over time off is not a social gradient: workers in education, health, personal services and manufacturing have less control over time off. Workers in bigger establishments have less control over time off. Within an industry and an establishment, higher-status occupations have more control over time off.

H2b: Control over time off is explained by work context more so than by social position.

\section{Autonomy in work organization}

Workers also have varying leeway in deciding what task to handle at a given time: while teachers and doctors are in charge of organizing their work (Boisard et al. 2003), assembly-line workers are not, and deviation from instructions could potentially endanger the production system and their position with it (Linhart 1981). Some occupations are intrinsically more reliant on autonomy in work organization regardless of the industry or the establishment: managers and professionals are increasingly encouraged to make up and see through "projects", be in charge of their own time management in a horizontal network (Boltanski and Chiapello 2005), and can sometimes do so in their own home (Anttila et al. 2015; Possenriede and Plantenga 2014). This points to a hierarchical distribution of autonomy in work organization within the wage-earner population.

Freedom in work location and task organization requires to be reliant neither on machinery or specific infrastructures, nor on other workers and a rigid specialization of workers (Boisard et al. 2003), making it likely more available to non-manual sectors and smaller establishments. Yet even non-manual high-status workers, like knowledge workers, can lack autonomy in work organization depending on "work process" and 
how dependent their work is on others' work (Tammelin et al. 2017). On the other hand, a growing part of home-based or out-of-office workers are unqualified and occupy precarious positions in the labor market, yet are unsupervised and self-reliant in their work activity, combining low-status with high autonomy in work organization, although likely less so than high-status workers (Boulin et al. 2006).

H3a: Autonomy in work organization is not a strict social gradient: workers in higher social positions do have more autonomy in work organization, but workers in non-manual occupations have more autonomy regardless of their social position. Workers in bigger establishments have less autonomy in work organization.

$\mathrm{H} 3 \mathrm{~b}$ : Social position and work context are equally important in determining work organization.

\section{Data}

The data used is from the French Time-Use Survey, conducted from September 2009 to September 2010 by the French office for national statistics (Insee) and is representative of the French population. The survey sample included 17800 households, of which 12069 responded. The analysis was limited to the employee population in employment and excluded French Overseas Departments and Territories inhabitants. Self-employed people are excluded as they were not asked about their temporal working conditions, and their inclusion tends to skew the results towards an opposition between self-employed workers and employees (Pailhé and Solaz 2009). The final sample is comprised of 8086 individuals, excluding 123 respondents with missing values.

\section{Methodology}

\section{Measuring Temporal Autonomy}

Expanding our understanding of temporal autonomy requires to capture its multiple dimensions. I thus conduct a Multiple Correspondence Analysis on 13 selected indicators of temporal autonomy, in order to identify interrelations between them. By providing orthogonal and hierarchical empirical dimensions, the MCA allows me to discern distinct aspects of temporal autonomy. Descriptive statistics on all indicators are presented in appendix I and detailed results and sensitivity analyses are presented in appendix II.

Three indicators relate to control over work time. The first is determination of work hours (either imposed by the employer, chosen by the employee, or negotiated between the two). The second indicator is whether respondents wished to change either their work hours or other hours. Combining freedom in work hours and wish to change work hours is more likely to capture actual autonomy in work schedules, as contractual right to choose or change hours does not necessarily translate into actually doing so, if work environment or work process do not allow it (Williams et al. 2013; Tammelin et al. 2017). For the same reason, a third indicator included is whether workers wished to work more, to capture control over the number of hours worked. This indicator offers 
insights into the elasticity of people's work hours and is the only available proxy for control over the number of hours worked (Lyness et al. 2012) available in the data.

Three variables capture unpredictability of schedules - not knowing one's schedule a day, a week and a month ahead. Keeping these three different timescales of predictability helps distinguish between daily, or at least, regular unpredictability often experienced by low-status occupations in demand-driven industries such as retail or care, from more incidental forms of unknown ${ }^{\mathrm{i}}$.

Control over time off was measured here by four indicators. Choosing break times and being able to leave work in case of unexpected events were included in the analysis (Boulin et al. 2006; Sweet et al. 2014). Duration of lunch break was also included, as having no lunch break or one outside of lunch time has been connected to imposed schedules (Bernard, 2007), while hours-long ones could indicate imposed fragmented schedules. Finally, long-term control over time off is captured by choice of vacation dates. Some have considered the ability to refuse to work overtime as a decisive aspect of temporal autonomy (McCann 2007), but it could not be included here as the question on overtime did not distinguish between chosen and imposed overtime and was not asked to all employees.

Finally, three indicators capture autonomy in work organization: having to clock-in, bringing work home (whether it is an option, and how frequently it happens), and work location. Including both the location of work and bringing work home allows me to dissociate very different situations in terms of temporal autonomy, between highstatus occupations working in offices yet having the option to continue working at home (facilitating family obligations), and "home" workers, in care work for instance, whose activity depends on their clients' presence and cannot be conducted at another time or place.

\section{Explaining Multiple Dimensions of Temporal Autonomy}

Respondents' coordinates on the first three axes are then standardized and used as dependent variables in OLS regression models. In order to test whether temporal autonomy reproduces a hierarchical ordering of social positions, the main explanatory variable introduced in the model is occupation, measured by the French occupational two-digits socio-professional categories ${ }^{\mathrm{ii}}$. Other indicators of social position introduced are income and level of education. Industry and size of the establishment are included as organizational characteristics in a second series of models, in order to assess their mediating effect. If temporal autonomy is a cumulative and hierarchically distributed resource, coefficients should become positive for higher-status occupations and negative for lower-status occupations, once organizational characteristics are included. If some dimensions of temporal autonomy are not hierarchically distributed, coefficients should not be all positive for higher-status and all negative for lower-status occupations, and organizational characteristics should have a strong and significant effect.

Control variables are gender, age, employment status, seniority, sector of employment (private or public), size of the urban unit, type of household, number and age of children and level of education of both parents. Reliable measures of part-time 
work are not available in this specific survey; daily work hours were included as a proxy and were not significant, nor changed significance in other coefficients, and were thus not included in the final model. Missing values for independent or control variables were imputed ${ }^{\text {iii }}$. Tests for multicollinearity indicate corrected measures of variance inflated factors under $2^{\text {iv }}$.

Squared semi-partial correlation coefficients are then computed to assess the size of the hierarchical and organizational effects for each dimension. They measure the proportion of variance in the dependent variable (coordinates) accounted for by a given variable, once all others are accounted for, which amounts to the difference in $\mathrm{R}^{2}$ between the full model and a model excluding said variable (Cohen et al. 2003). A high coefficient for occupation combined with high coefficients for income, education and other indicators of social position, and lower coefficients for size of establishment and industry would suggest the hierarchical effect overrides the organizational effect of occupation, and vice versa.

Finally, descriptive statistics on the distribution of coordinates are conducted to test for homogeneity within (and heterogeneity between) more aggregated and hierarchical groups of positions - i.e. managers and professionals, intermediate professions, employees and manual workers (Deauvieau et al., 2014). If a hierarchical effect prevails, coordinates should be relatively homogeneous within a social group, and heterogenous between different groups; on the other hand, if the "activity-specific" effect is dominant, there should be high variability within each social group, and no clear hierarchical order between them.

\section{Results}

\section{Three dimensions of temporal autonomy}

The MCA shows the first three dimensions capture the most relevant information (based on the elbow method, see figure A in appendix II) ${ }^{\mathrm{v}}$, which is corroborated by the lack of interpretability of the remaining axes. The cloud of active categories on the first two plans (figures $1 \mathrm{a}$ and $1 \mathrm{~b}$ ) shows that some categories are more discriminant than others: more specifically, being able to choose one's work hours, having unpredictable schedules for the month, the week and even more so the day ahead and working from home seem to be relatively selective forms of temporal autonomy, as indicated by their positions either on the far right of the first axis or the very top of the third axis, while knowing one's schedule ahead and being unable to choose work hours remain relatively close to the axis center, although distinctly to the left. This unequal structure is corroborated by the clouds of individuals (figures B and C in appendix II), which display a greater concentration of respondents on the left-hand side and a more dispersed cloud on the right-hand side ${ }^{\mathrm{vi}}$. This suggests a strongly unequal structure of temporal autonomy, better described by investigating the composition of each axis. 
Figure 1a: Active modalities on the first plan (1-2)

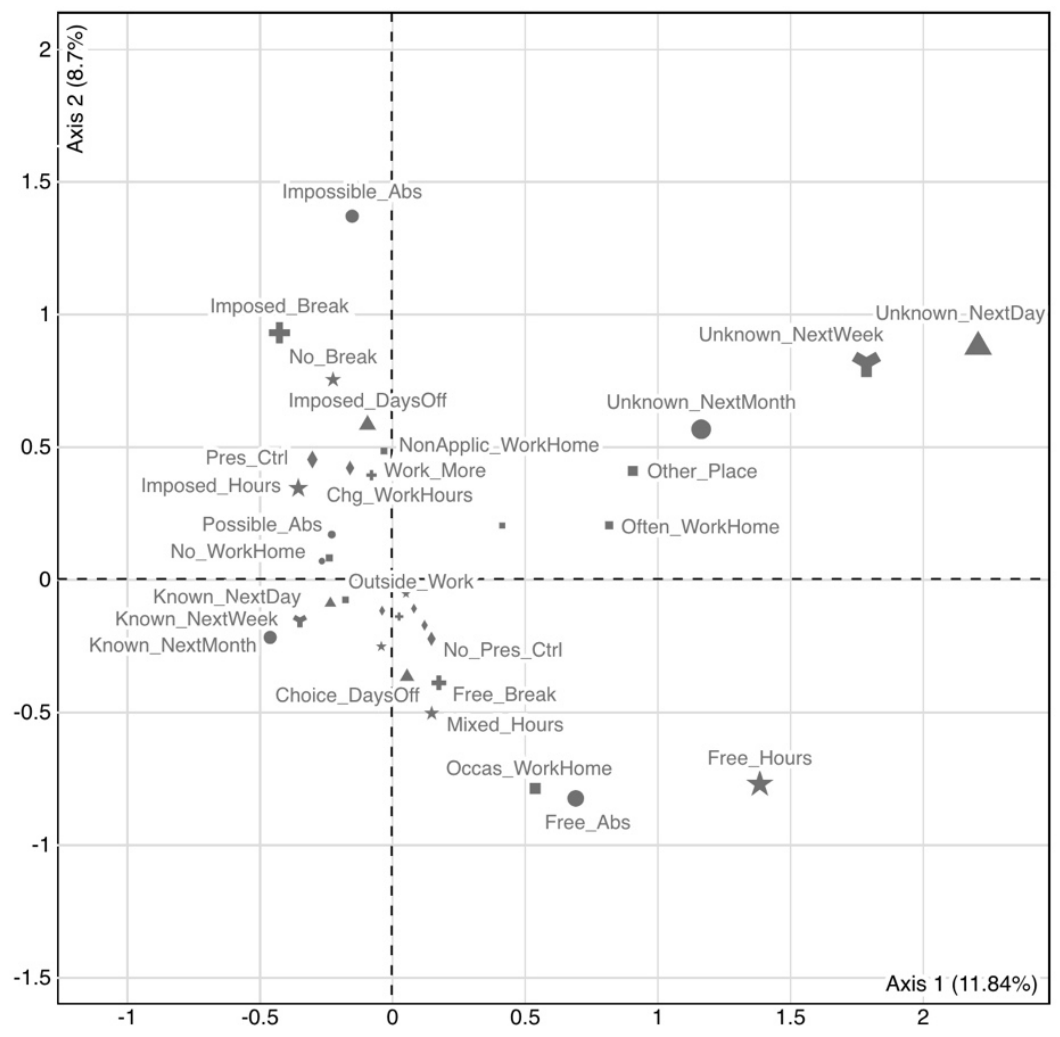

Source: French Time-Use Survey 2010

Note: The MCA analysis is weighted with a standardized individual weighting variable available in the database. Modalities contributing for less than $0,1 \%$ are not displayed here.

Figure 1b: Active modalities on the second plan (1-3)

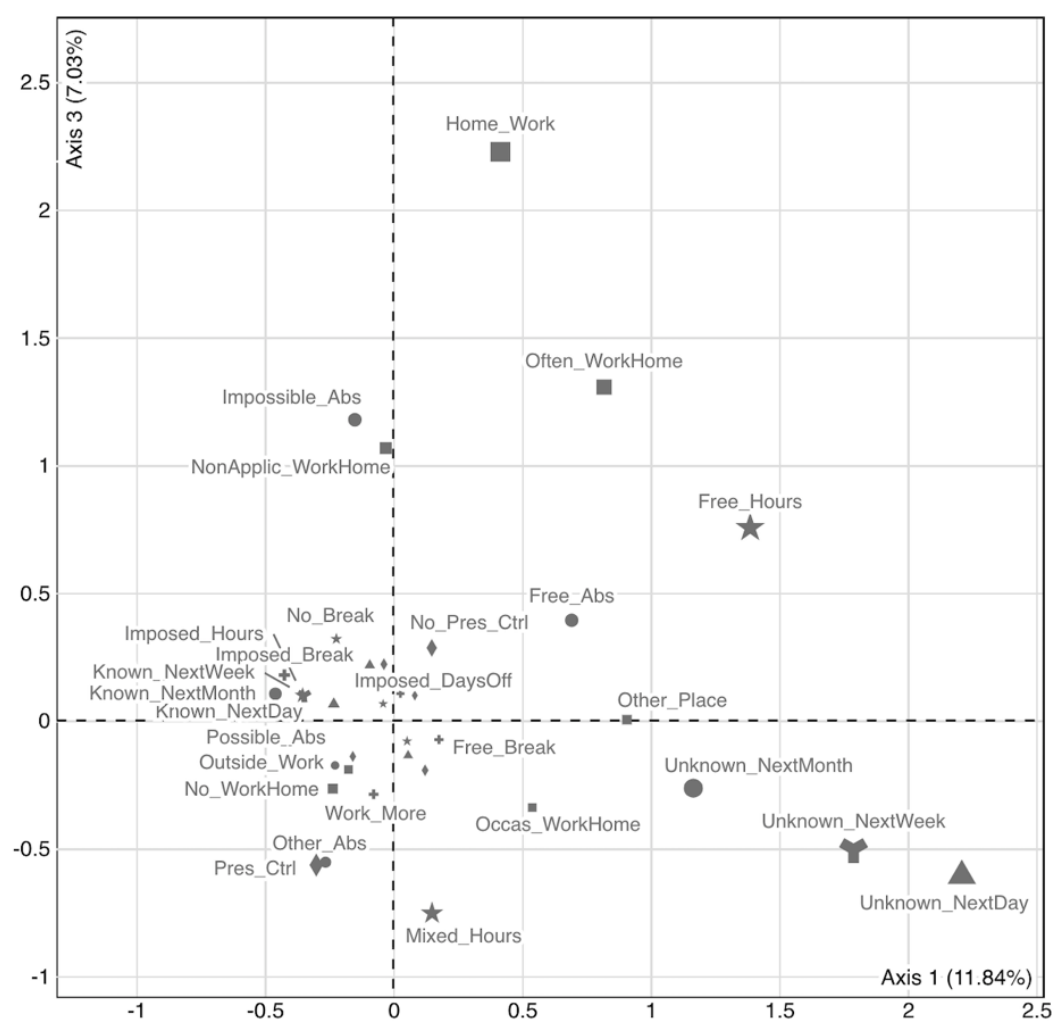


The first axis, which accounts for $67,7 \%$ of variability in the sample, is mostly and positively determined by control over work schedules and unpredictability of schedules: workers with the most autonomy would have both contractual leeway in choosing their work hours, and the option to change them on a day-to-day basis. This first dimension seems to capture both control and adaptability of work time.

The second axis, explaining $22 \%$ of the overall variability within the sample, opposes workers who are unable to choose when to take a break, unable to leave their workplace if they have a personal obligation, and unable to choose when to take days off on the one hand, and workers free to take a break and to leave work on specific occasions on the other hand ${ }^{\text {vii }}$. This dimension thus dissociates all forms of freedom in time off from all forms of constraints in time off, capturing control over time off.

Finally, the third axis, explaining 7,8\% of the variability in the sample, distinguishes between workers whose work hours are negotiated with their employer and who have to clock in at the bottom of the axis, and workers working either exclusively from home or who bring work home regularly at the top of the axis. The former would be less autonomous and under more direct hierarchical supervision; the latter would have more freedom in arranging and organizing their tasks at their own discretion. This dimension therefore seems to be driven by autonomy in work organization.

\section{Temporal autonomy as a product of social positions}

In order to discern whether control and adaptability of work time is a resource granted to workers with higher social status, or the product of working in white-collar, nonmanual industries ; whether control over time off is gradually more available as social positions increase, or specific to an establishment with fewer schedules to coordinate, or industries which do not rely on lean manufacturing; or whether workers get more autonomy in their work organization as a privilege or as a specificity of the task they are asked to perform, two series of regression models are presented in table 1. Results on control and adaptability of work time (dimension 1) indicate a linear effect of social position, with high-status occupations such as managers and engineers associated with much more autonomy, and low-status occupations such as skilled and unskilled labor with much less autonomy than administrative employees, once organizational characteristics are controlled for (model 2). This linear gradient also seems to be confirmed by the effect of income, with significant, positive and gradually bigger coefficients as income increases. On the other hand, coefficients in model 1 (without controls for organizational characteristics) are not linearly ordered according to social position. This brings strong support for hypothesis $1 \mathrm{a}$.

On control over time off (dimension 2), occupation has a rather non-linear effect, and coefficients for occupations are stable across both models ( 3 and 4). While all coefficients for positions in the two lower-status groups of routine non-manual workers and manual workers are negative, higher positions have two opposite effects. Managers and engineers are, here again, associated with more autonomy, while 
teachers and information and entertainment occupations are associated with less. This could be explained by the specific activities their occupation entails, making them unable to leave a classroom or pause during a performance.

Autonomy in work organization, the third dimension, highlights similar nonlinear patterns in how temporal autonomy is distributed across occupations, and coefficients for occupations are relatively unchanged by the inclusion of organizational characteristics. In a 24-categories occupational scheme, care workers are highly autonomous, unlike unskilled industrial labor and retail workers, in spite of their relatively similar social positions (see appendix III) ; and managers only seem more autonomous in administrative or commercial activities but not in technical activities, while public service executives are less autonomous in spite of their higher social status than the reference category. This suggests that the effect of social positions on autonomy in work organization is less instrumental than anticipated and could be offset by broader work context.

Table 1 - OLS models on the three dimensions of temporal autonomy

\begin{tabular}{|c|c|c|c|c|c|c|c|}
\hline & & \multicolumn{2}{|c|}{ Dim 1} & \multicolumn{2}{|c|}{$\operatorname{Dim} 2$} & \multicolumn{2}{|c|}{$\operatorname{Dim} 3$} \\
\hline Variables & Modalities & Model 1 & Model 2 & Model 3 & Model 4 & Model 5 & Model 6 \\
\hline \multirow[t]{2}{*}{ Intercept } & (Intercept) & $-0.23 * * *$ & $-0.19 * *$ & $0.28 * * *$ & $0.43 * * *$ & $-0.53 * * *$ & $-0.55 * * *$ \\
\hline & & $(0.08)$ & 0.08 & $(0.07)$ & 0.08 & $(0.07)$ & 0.07 \\
\hline \multirow[t]{2}{*}{ Sex } & Women & $-0.17 * * *$ & $-0.16 * * *$ & -0.05 & -0.04 & -0.01 & $-0.07 * * *$ \\
\hline & & $(0.03)$ & 0.03 & $(0.03)$ & 0.03 & $(0.03)$ & 0.03 \\
\hline \multirow{20}{*}{$\begin{array}{l}\text { Occupation } \\
\text { (PCS) }\end{array}$} & Managers, engineers & $0.53 * * *$ & $0.58 * * *$ & $0.31 * * *$ & $0.30 * * *$ & 0.06 & 0.05 \\
\hline & & $(0.07)$ & 0.07 & $(0.06)$ & 0.06 & $(0.06)$ & 0.06 \\
\hline & Higher Intellectual & $0.28 * * *$ & $0.52 * * *$ & $-0.65 * * *$ & $-0.42 * * *$ & $1.00 * * *$ & $0.72 * * *$ \\
\hline & & $(0.09)$ & 0.10 & $(0.08)$ & 0.09 & $(0.09)$ & 0.09 \\
\hline & Primary Educ. Teachers & -0.06 & $0.23 * * *$ & $-0.86 * * *$ & $-0.49 * * *$ & $1.04 * * *$ & $0.58 * * *$ \\
\hline & & $(0.07)$ & 0.08 & $(0.08)$ & 0.10 & $(0.08)$ & 0.09 \\
\hline & Health Workers & -0.01 & $0.16^{* *}$ & $-0.36 * * *$ & $-0.37 * * *$ & $0.22 * * *$ & $0.16^{* *}$ \\
\hline & & $(0.07)$ & 0.08 & $(0.07)$ & 0.08 & $(0.06)$ & 0.06 \\
\hline & Intermediate Professions & $0.33 * * *$ & $0.40 * * *$ & 0.03 & 0.04 & -0.08 & $-0.10 * *$ \\
\hline & & $(0.06)$ & 0.06 & $(0.06)$ & 0.05 & $(0.05)$ & 0.05 \\
\hline & Civil servants & $-0.12 * *$ & 0.08 & $-0.38 * * *$ & $-0.38 * * *$ & 0.06 & 0.01 \\
\hline & & $(0.05)$ & 0.06 & $(0.06)$ & 0.07 & $(0.05)$ & 0.06 \\
\hline & Employees - other & $0.11 * *$ & 0.03 & $-0.48 * * *$ & $-0.53 * * *$ & $0.45 * * *$ & $0.14 * *$ \\
\hline & & $(0.05)$ & 0.06 & $(0.06)$ & 0.07 & $(0.06)$ & 0.06 \\
\hline & Manual Skilled & $-0.19 * * *$ & $-0.12 * *$ & $-0.46 * * *$ & $-0.43 * * *$ & -0.00 & -0.05 \\
\hline & & $(0.06)$ & 0.06 & $(0.06)$ & 0.06 & $(0.05)$ & 0.05 \\
\hline & Manual Transport & $0.35 * * *$ & $0.38 * * *$ & $-0.95 * * *$ & $-0.77 * * *$ & -0.10 & -0.06 \\
\hline & & $(0.09)$ & 0.09 & $(0.09)$ & 0.09 & $(0.07)$ & 0.07 \\
\hline & Manual Unskilled & -0.04 & -0.02 & $-0.45 * * *$ & $-0.45 * * *$ & 0.01 & -0.07 \\
\hline & & $(0.07)$ & 0.07 & $(0.07)$ & 0.07 & $(0.06)$ & 0.06 \\
\hline \multirow[t]{8}{*}{ Education } & Higher education $(>2 y)$ & -0.03 & 0.01 & $0.20 * * *$ & $0.21 * * *$ & -0.03 & -0.02 \\
\hline & & $(0.05)$ & 0.05 & $(0.04)$ & 0.04 & $(0.04)$ & 0.04 \\
\hline & Higher education $(<2 y)$ & -0.05 & -0.03 & $0.13 * * *$ & $0.12 * * *$ & $-0.08 * *$ & -0.05 \\
\hline & & $(0.05)$ & 0.05 & $(0.04)$ & 0.04 & $(0.04)$ & 0.04 \\
\hline & Baccalaureate & -0.02 & -0.02 & 0.05 & 0.03 & -0.03 & 0.01 \\
\hline & & $(0.05)$ & 0.05 & $(0.04)$ & 0.04 & $(0.04)$ & 0.04 \\
\hline & No degree & -0.04 & -0.06 & -0.03 & -0.03 & $0.09 * *$ & $0.07 *$ \\
\hline & & $(0.04)$ & 0.04 & $(0.04)$ & 0.04 & $(0.04)$ & 0.04 \\
\hline \multirow{8}{*}{$\begin{array}{l}\text { Income } \\
\text { quintile }\end{array}$} & $1 \mathrm{st}$ & $0.15^{* * *}$ & 0.07 & -0.03 & -0.04 & $0.26 * * *$ & $0.09 * *$ \\
\hline & & $(0.05)$ & 0.05 & $(0.05)$ & 0.05 & $(0.05)$ & 0.04 \\
\hline & $3 \mathrm{rd}$ & $0.17 * * *$ & $0.17 * * *$ & $0.06^{*}$ & $0.08 * *$ & 0.00 & 0.01 \\
\hline & & $(0.03)$ & 0.03 & $(0.03)$ & 0.03 & $(0.03)$ & 0.03 \\
\hline & 4 th & $0.57 * * *$ & $0.59 * * *$ & $0.16^{* * *}$ & $0.19 * * *$ & $0.13 * * *$ & $0.18 * * *$ \\
\hline & & $(0.06)$ & 0.06 & $(0.05)$ & 0.05 & $(0.05)$ & 0.05 \\
\hline & 5 th & $0.74 * * *$ & $0.72 * * *$ & $0.24 * *$ & $0.25 * *$ & $0.56 * * *$ & $0.65 * * *$ \\
\hline & & $(0.12)$ & 0.12 & $(0.10)$ & $(0.10)$ & $(0.12)$ & $(0.12)$ \\
\hline \multirow{3}{*}{$\begin{array}{l}\text { Employment } \\
\text { sector }\end{array}$} & Government employee & & $-0.14 * * *$ & & -0.00 & & $0.09 * *$ \\
\hline & & & $(0.05)$ & & $(0.05)$ & & $(0.05)$ \\
\hline & Local government & & $-0.21 * * *$ & & $0.19^{* * *}$ & & $0.12 * *$ \\
\hline
\end{tabular}




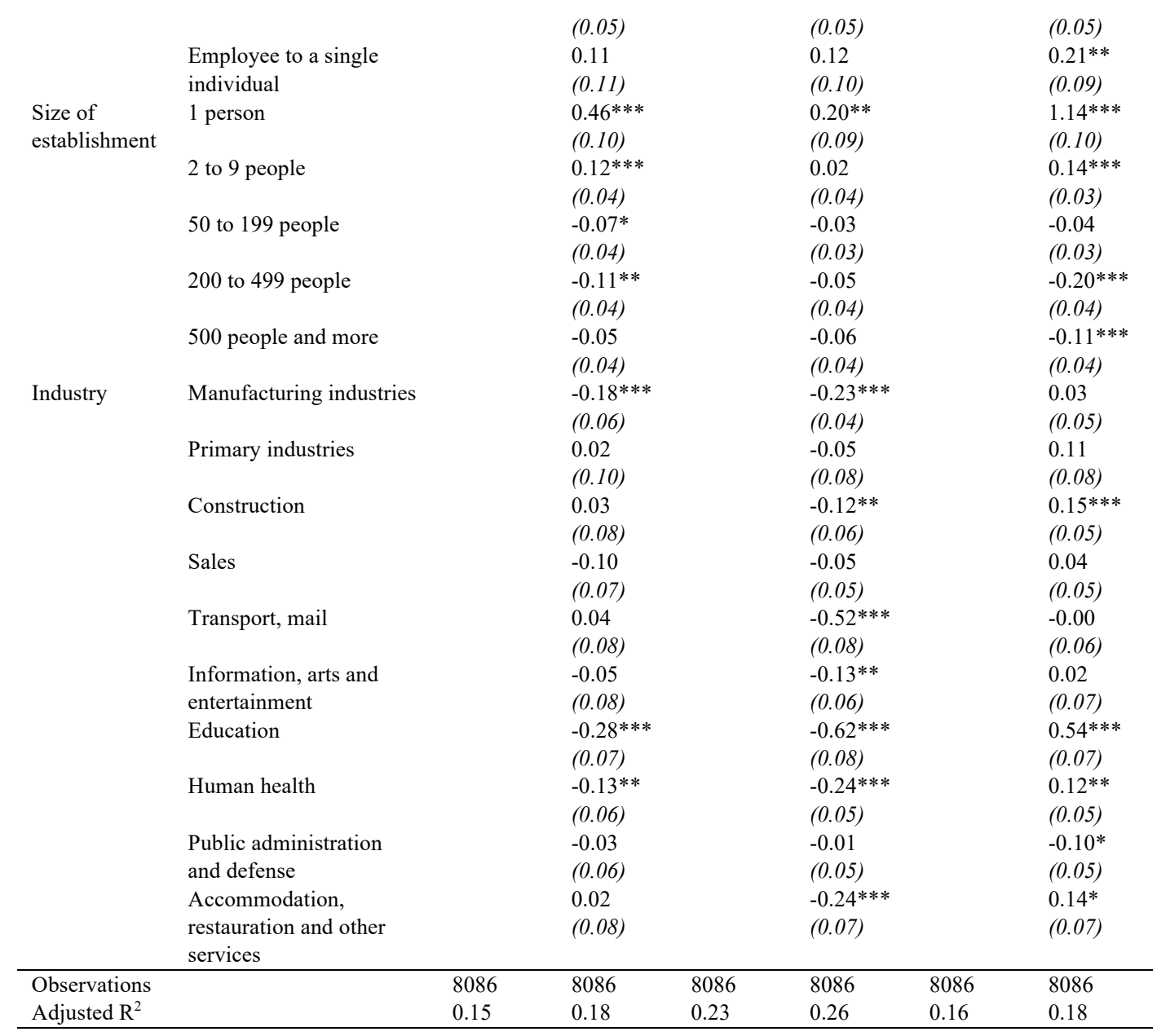

Source: French Time-Use Survey 2010

Note: $p<0,1: * ; p<0,05: * * ; p<0,01: * * *$. OLS models are weighted with a standardized individual weighting variable available in the database. Standard deviations are in parentheses.

\section{Mediating effect of work context}

A look at the effect of industry further corroborates hypothesis 1a: industry is overall not significant in determining control and adaptability of work time, with the exception of education and health, both detrimental to this form of autonomy. This is no longer the case for the second dimension of autonomy, where the effect of industry is both more significant and stronger. In line with hypothesis $2 \mathrm{a}$, workers in education, health, personal services and manufacturing have less control over time off than workers in financial and administrative services. However, size of establishment, which was expected to be fairly significant, is not. Although the only significant estimate does corroborate hypothesis $2 \mathrm{a}$, with establishments of over 500 people having a negative effect on freedom to stop working, the overall non-significance of this variable jeopardizes the idea that this dimension is strongly determined by the coordination costs of work schedules. Instead, these results suggest that industry- and activityspecific rhythms are more likely to explain being able to stop working on a daily or long-term basis. 
Hypothesis 3a stated that autonomy in work organization was more prevalent in non-manual occupations and small-sized establishments. The effect of the size of establishment is as expected: significant overall, positive for establishments with under 50 employees and negative for establishments with over 50 employees. However, the effect of industry is more puzzling: compared to financial and administrative services, almost all industries, including manufacturing, primary activities and construction, enhance autonomy in work organization ${ }^{\text {viii }}$. This confounding effect suggests industryspecific time related constraints might play a rather secondary role in shaping workers' autonomy in work organization, upstaged by direct work environment.

\section{Occupation as the main determinant: a hierarchical effect?}

So far, two conclusions arise: first, occupation is highly determinant in explaining all three dimensions of temporal autonomy; second, its effect differs from one dimension to another. However, clarifying this effect and assessing its importance requires additional analyses. Table 2 displays squared semi-partial correlation coefficients for all variables included in the model, on all three dimensions. In accordance with H1b, occupation is the most determinant variable on the first dimension, followed by income, while size and industry have small explanatory power.

\section{Table 2: Squared semi-partial correlation coefficients on OLS models}

\begin{tabular}{lrrr} 
& \multicolumn{3}{c}{$\mathrm{sr}^{2}($ in \%) } \\
\cline { 2 - 4 } Variable & Axis 1 & Axis 2 & Axis 3 \\
\hline Occupation & 19.67 & 21.72 & 8.65 \\
Income & 10.38 & 1.12 & 3.38 \\
Education & 0.55 & 1.12 & 0.38 \\
Industry & 3.83 & 9.74 & 6.77 \\
Size & 4.37 & 0.75 & 16.17 \\
Sector & 1.64 & 1.12 & 0.75 \\
Contract & 1.64 & 0.75 & 0.38 \\
Seniority & 2.19 & 1.12 & 0.00 \\
Gender & 2.19 & 0.00 & 0.38 \\
Age & 1.09 & 1.87 & 1.88 \\
Family situation & 0.55 & 0.00 & 1.88 \\
Pres/age of children & 1.09 & 0.37 & 0.38 \\
Size of urban unit & 3.28 & 0.00 & 0.00 \\
Mother's education & 0.55 & 0.37 & 0.00 \\
Father's education & 0.55 & 0.37 & 0.00 \\
\hline
\end{tabular}

Source: French Time-Use Survey 2010

Note: $\mathrm{sr}^{2}$ are presented here as the percentage of explanatory power $\left(\mathrm{R}^{2}\right)$ lost when removing each variable from the model rather than as the straightforward difference between the two $\mathrm{R}^{2}$, for ease of interpretation. For instance, removing occupation from model 1 (resp. 2, 3) leads to a loss of $19,7 \%$ (resp. $21,7 \%, 8,6 \%$ ) of explanatory power.

Occupation is also highly determinant of the second dimension, as is industry, but not size of establishment, making it harder to discern an organizational effect from a hierarchical one, and thus to either support or reject H2b. On the other hand, organizational characteristics do seem to prevail in determining autonomy in work organization. The very limited explanatory power of any hierarchical indicators such as income or education on the third axis, with a weakened effect of occupation compared to size and industry combined suggests hypothesis $3 \mathrm{~b}$ should be rejected. 
Boxplots of the distribution of coordinates for four aggregated groups of social positions provide an additional, straightforward test for hypotheses $1 \mathrm{~b}, 2 \mathrm{~b}$ and $3 \mathrm{~b}$. These four groups are clearly and significantly hierarchically ordered on the first dimension, control and adaptability of work time, and clearly and significantly not so on the third dimension, autonomy in work organization (see figures $2 \mathrm{a}$ and $2 \mathrm{c}$ ). Results are, once again, less clear for control over time off, where routine non-manual and manual workers have relatively comparable median coordinates, lower than that of intermediate professions and managers. Ultimately, social position seems fairly important in explaining control over time off, and hypothesis $2 b$ cannot be fully validated.

Figure 2a: Boxplots of coordinates depending on occupation (axis 1).

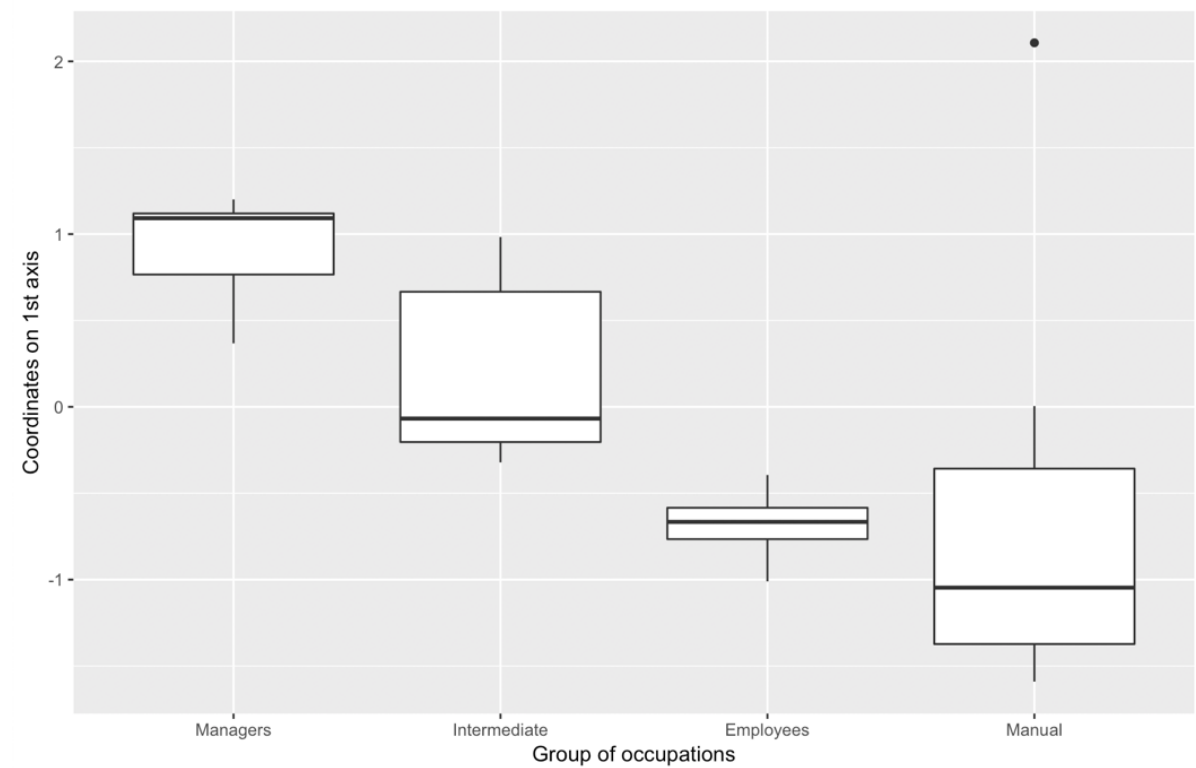

Figure 2b: Boxplots of coordinates depending on occupation (axis 2).

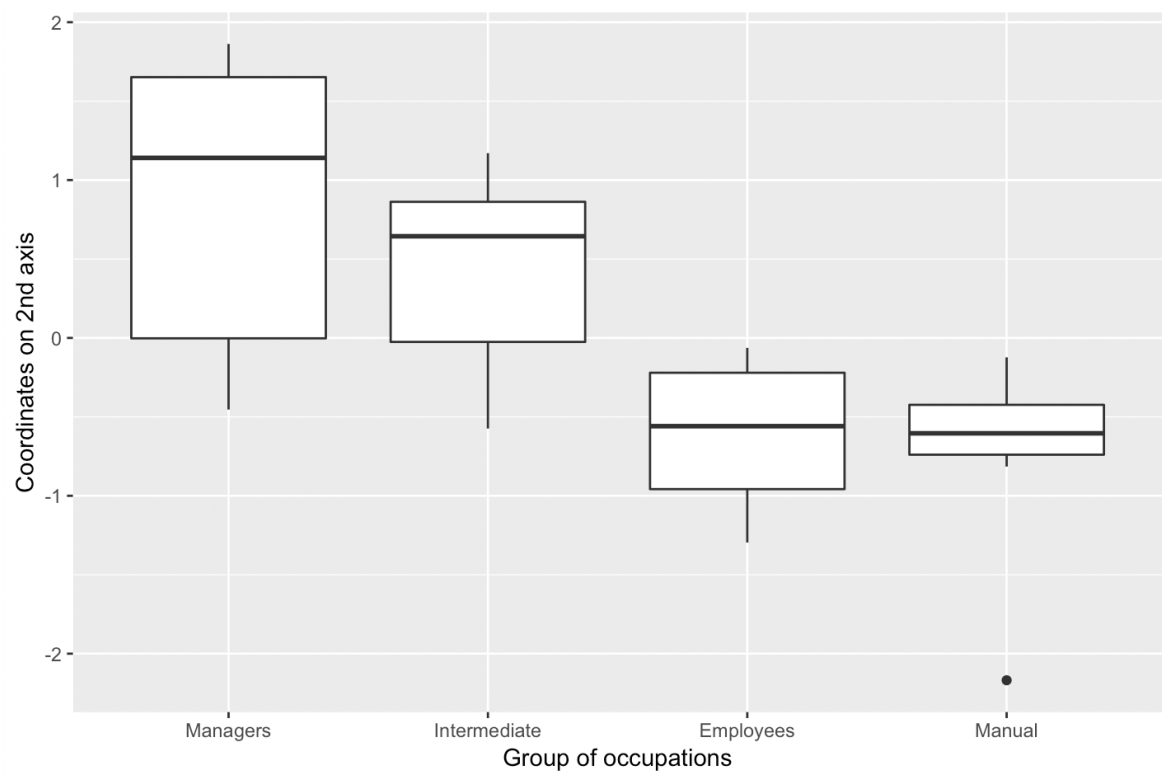


Figure 2c: Boxplots of coordinates depending on occupation (axis 3).

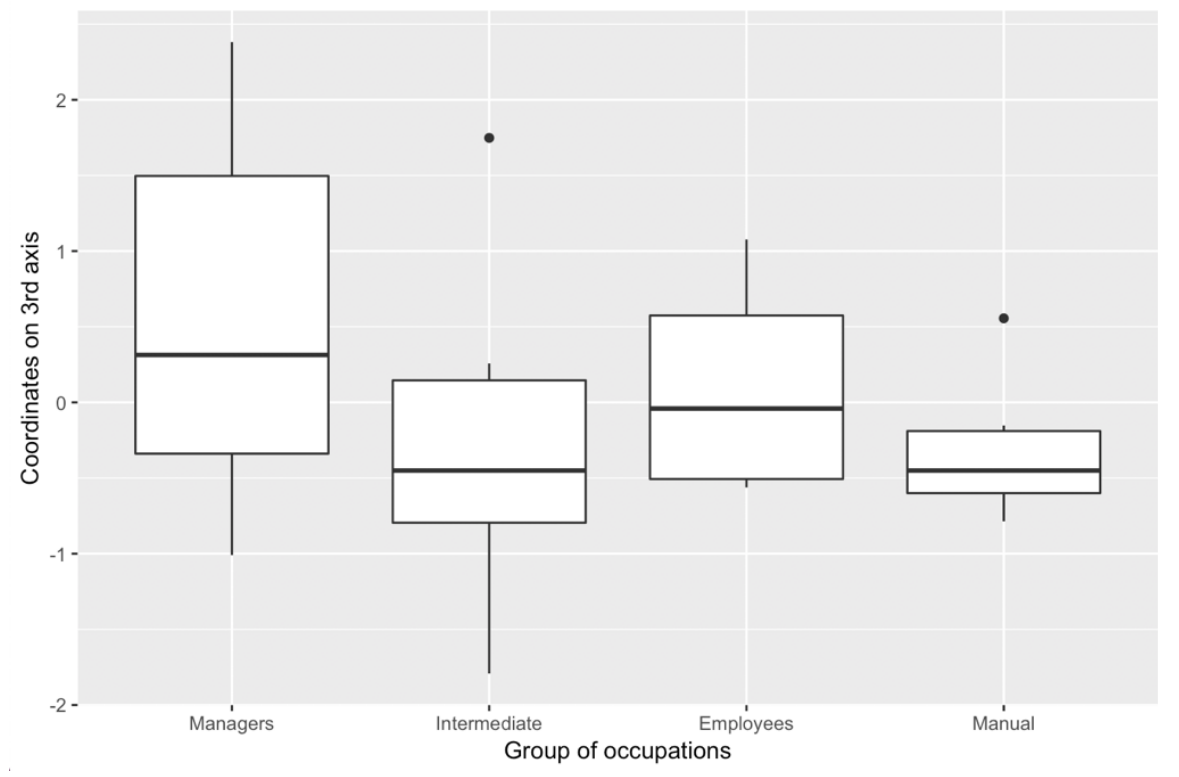

\section{Discussion}

This paper's contributions are twofold. First, it provides accurate yet easily interpretable measures of temporal autonomy which take into account a wider scope of time constraints: control and adaptability of work time; control over time off; and autonomy in work organization. Second, it sheds light on the effect of social position on temporal autonomy. By attempting to disentangle a hierarchical effect of occupation from an activity-specific one, it helps clarify relatively inconsistent or imprecise results on whether temporal autonomy is a linearly distributed resource. Social position is a decisive determinant of temporal autonomy, and its effect is most significant on control over and adaptability of work time, but is mediated by work context on control over time off and even more so on autonomy in work organization.

This result confirms previous studies on control over work time in finding highly qualified, privileged workers to have more freedom in shaping their work schedules than workers in more precarious positions (Lesnard 2008; Gerstel and Clawson 2018), and builds on it by specifying the type of autonomy these workers get, which extends to control over time off and over work organization. While some occupations were found to accumulate all forms of temporal autonomy, others rely on one. Care workers for instance, benefit from great autonomy in work organization but lack control over when to work and when to stop. In that sense, investigating different dimensions of autonomy allows me to shed light on a cumulative aspect of temporal autonomy which is often overlooked, yet crucial to understanding how inequalities in time allocation are created at work and passed on off work. 
Further investigation of this question could focus on integrating potential sources of constraints not captured here: work environment, work "commitment" and work process. For instance, having control over work time might be curved by a "flexibility stigma" in which deliberately taking time off work is frowned upon and perceived as a lack of personal investment (Williams et al. 2013), as in "highcommitment" occupations (Berg et al. 2003) encouraging workers to voluntarily spend more time at work (Hochschild 1997; Gershuny 2005). Temporal autonomy could also be impeded by work overload (Skinner and Pocock 2018) or by a demanding work process, creating an "illusion" of temporal autonomy for workers whose activity depends on others' or, perhaps most importantly, whose activity allows others to do theirs (Tammelin et al. 2017). If such is the case in France, a more thorough study of temporal autonomy including indicators of work environment and work process could possibly unveil new ways in which distribution of temporal autonomy is unequally distributed.

However, this paper raised a specific question beyond measurement issues. The multidimensional definition of temporal autonomy proposed here could prove to be a powerful tool to grasp occupational - and as such, class - inequalities, and understand its gendered consequences, as temporal autonomy at work shapes daily arrangements off work. By better identifying the occupations and organizations whose work time constraints are most difficult and cumulative, this paper could ultimately provide guidance as to where and for whom to elaborate and implement policies in a growingly deregulated labor market with relatively few "work-life" initiatives in place (Lesnard 2008; Ollier-Malaterre 2009).

\section{References}

Allison, P. 2012. "When Can You Safely Ignore Multicollinearity?" Statistical Horizons, September.

Anttila, T., Oinas, T., Tammelin, M. and Nätti, J. 2015. "Working-Time Regimes and Work-Life Balance in Europe.” European Sociological Review 31 (6): 71324.

Berg, P., Bosch, G. and Charest, J. 2014. "Working-Time Configurations: A Framework for Analyzing Diversity across Countries." Industrial and Labor Relations Review, 67 (3): 805-37.

Berg, P., Kalleberg, A.L. and Appelbaum, E. 2003. "Balancing Work and Family: The Role of High-Commitment Environments." Industrial Relations 42 (2): 16888.

Bernard, S. 2007. “Cashiers' Work-Time: Between a Productivity Mentality and a Service Mentality". Sociologie Du Travail 49 (december): 129-144.

Boisard, P., Cartron, D., Gollac, M. and Valeyre, A. 2003. "Time and Work: Work Intensity." Ireland: European Foundation for the Improvement of Living; Working Conditions.

Boltanski, L. and Chiapello, E. 2005. The New Spirit of Capitalism. Translated by Gregory Elliott. 2018th ed. London: Verso. 
Boulin, J-Y., Lallement, M., Messenger, J.C. and Michon, F. eds. 2006. Decent Working Time: New Trends, New Issues. Geneva: International Labour Office.

Bourdieu, P. 1979. Algeria 60. Translated by Richard Nice. Cambridge University Press.

Clawson, D. and Gerstel, N. 2014. Unequal Time. Gender, Class, and Family in Employment Schedules. Russel Sage Foundation.

Cohen, J., Cohen, P., West, S.G. and Aiken, L.S. 2003. Applied Multiple Regression/Correlation Analysis for the Behavioral Sciences. Third. Lawrence Erlbaum Associates.

Conk, M.A. 1978. "Occupational Classification in the United States Census: 18701940." Journal of Interdisciplinary History 9 (1): 111.

Deauvieau, J., Penissat E., Brousse, C., Jayet, C. and Hamilton, P. 2014. "Everyday Categorisations of French Social Space: Analysis Based on a Card Game.” Revue Française de Sociologie (English Edition) 55 (3): 280-323.

Drago, R., Wooden, M. and Black D. 2009. "Who Wants and Gets Flexibility? Changing Work Hours Preferences and Life Events." Industrial and Labour Relations Review 62 (3): 394-414.

Eaton, S.C. 2003. "If You Can Use Them: Flexibility Policies, Organizational Commitment, and Perceived Performance." Industrial Relations: A Journal of Economy and Society 42 (2): 145-67.

Estrade, M. and Ulrich, V. 2002 "La réorganisation des temps travaillés et les 35 heures : un renforcement de la segmentation du marché du travail." Travail et Emploi, 92 : 71-94.

Fagan, C. 2001. "The Temporal Reorganization of Employment and the Household Rhythm of Work Schedules.” American Behavioral Scientist, 44 (7) : 1199-1212.

Gershuny, J. 2005. "Busyness as the Badge of Honor for the New Superordinate Working Class." Social Research, 287-314.

Gerstel, N. and Clawson, D. 2018. "Control over Time: Employers, Workers, and Families Shaping Work Schedules.” Annual Review of Sociology 44: 9.1-9.21.

Glauber, R. 2011. "Limited Access: Gender, Occupational Composition, and Flexible Work Scheduling." The Sociological Quarterly 52 (3): 472-94.

Golden, L. 2001. "Flexible Work Schedules: Which Workers Get Them?" American Behavioral Scientist 44 (7): 1157-78.

Henly, J.R. and Lambert, S.J. 2014. "Unpredictable Work Timing in Retail Jobs: Implications For Employee Work-Life Conflict." Industrial and Labor Relations Review 67 (3): 986-1016.

Hochschild, A.R. 1997. The Time Bind. When Work Becomes Home and Home Becomes Work. Henry Holt; Company.

Hodson, R. 2001. Dignity at Work. Cambridge; New York: Cambridge University Press.

Kalleberg, A.L. 2011. Good Jobs, Bad Jobs: The Rise of Polarized and Precarious Employment Systems in the United States, 1970s to 2000s. New York: Russel Sage Foundation. 
Kelliher, C. and Anderson, D. 2010. "Doing More with Less? Flexible Working Practices and the Intensification of Work." Edited by Ellen Ernst Kossek, Susan Lewis, and Leslie B Hammer. Human Relations 63 (1): 83-106.

Kerkhofs, M., Chung, H. and Ester, P. 2008. "Working Time Flexibility Across Europe: A Typology Using Firm-Level Data.” Industrial Relations Journal 39 (6): 569-85.

Lambert, A.D., Marler, J.H. and Gueutal, H.G. 2008. "Individual Differences: Factors Affecting Employee Utilization of Flexible Work Arrangements." Journal of Vocational Behavior 73 (1): 107-17.

Le Roux, B., and Rouanet, H. 2010. Multiple Correspondence Analysis. SAGE.

Lehndorff, S. 2014. "It's a Long Way from Norms to Normality: The 35-Hour Week in France." ILR Review 67 (3): 838-63.

Lesnard, L. 2008. "Off-Scheduling Within Dual-Earner Couples: An Unequal and Negative Externality for Family Time.” American Journal of Sociology 114 (2): 447-90.

Linder, M. and Nygaard, I. 1998. Void Where Prohibited: Rest Breaks and the Right to Urinate on Company Time. ILR Press.

Linhart, R. 1981. The Assembly Line. University of Massachusetts Press.

Lyness, K.S., Gornick, J.C., Stone, P. and Grotto, A.R. 2012. "It's All About Control: Worker Control over Schedule and Hours in Cross-National Context." American Sociological Review 77 (6): 1023-49.

McCann, D. 2007. "Temporal Autonomy and the Protective Individualisation of Working-Time Law: The Case of Overtime Work." Labour \& Industry: A Journal of the Social and Economic Relations of Work 17 (3): 29-43.

McCrate, E. 2012. "Flexibility for Whom? Control over Work Schedule Variability in the US." Feminist Economics 18 (1): 39-72.

Ollier-Malaterre, A. 2009. "Organizational Work-life Initiatives: Context Matters: France Compared to the UK and the US." Community, Work \& Family 12 (2): 159-78.

Pailhé, A. and Solaz, A. 2009. Entre Famille et Travail. Des Arrangements de Couples Aux Pratiques Des Employeurs. Paris: La Découverte.

Possenriede, D., and Plantenga, J. 2014. "Temporal and Locational Flexibility of Work, Working-Time Fit, and Job Satisfaction.” IZA Discussion Paper 8436: 34.

Reynolds, J.E. 2014. "Prevailing Preferences: Actual Work Hours and Work-Hour Preferences of Partners." ILR Review 67 (3): 1017-41.

Sharma, S. 2014. In the Meantime: Temporality and Cultural Politics. Durham: Duke University Press.

Skinner, N. and Pocock, B. 2018. "Work-Life Conflict: Is Work Time or Work Overload More Important?” Asia Pacific Journal of Human Resources 46 (3): 13.

Sweet, S., Pitt-Catsouphes, M., Besen, E. and Golden, L. 2014. "Explaining Organizational Variation in Flexible Work Arrangements: Why the Pattern and Scale of Availability Matter." Community, Work \& Family 17 (2): 115-41. 
Tammelin, M., Koivunen, T. and Saari T. 2017. "Female Knowledge Workers and the Illusion of Working-Time Autonomy". International Journal of Sociology and Social Policy 37 (9/10): 591-604.

Thompson, E.P. 1967. “Time, Work-Discipline, and Industrial Capitalism.” Past \& Present, no. 38: 56-97.

van Buuren, S. and Groothuis-Oudshoorn, K. 2011. "Mice: Multivariate Imputation by Chained Equations in R." Journal of Statistical Software 45 (3).

Williams, J.C., Blair-Loy, M. and Berdahl, J.L. 2013. "Cultural Schemas, Social Class, and the Flexibility Stigma: Cultural Schemas and Social Class." Journal of Social Issues 69 (2): 209-34.

Wiswall, M., and Zafar, B. 2018. "Preference for the Workplace, Investment in Human Capital, and Gender". The Quarterly Journal of Economics 133 (1): 457 507.

\section{Endnotes}

\footnotetext{
${ }^{i}$ As a robustness test, these three variables were combined into a single indicator in order not to skew the results. While the associations between other variables remained unchanged, the significant loss of inertia combined with the sociologically irrelevant added modalities comforted the inclusion of three separate variables.

ii Three groupings of occupational categories were systematically analyzed (in 4, 11 and 24 categories) and results remained consistent across all groupings.

iii Variables with imputed values are: industry, size of the establishment, seniority and level of education of both parents. Imputation was done with the 'mice' package in R (van Buuren and GroothuisOudshoorn 2011).

iv This threshold is recommended by Allison (2012) in an online note.

v Using Benzécri's pseudo-eigenvalues formula (Le Roux and Rouanet 2010), the modified rates of inertia of the first three axes sum up to $97,5 \%$. The standard inertia rates amount to $27,6 \%$.

vi This type of structure could be artificially created by the inclusion of extremely rare modalities. Not knowing one's schedule a day, a week or a month ahead respectively represent $9,5 \%, 16,2 \%$ and $28,2 \%$ of the population, while $6,9 \%$ work from home and $9,4 \%$ bring work home regularly. As a robustness test, the analysis was conducted with all modalities under $10 \%$ as supplementary categories and remained unchanged (see table A for correlation coefficients between the coordinates from our main analysis and the robustness analyses).

vii For the sake of clarity, coordinates on the second axis were inverted, so that more autonomous workers are associated with positive coordinates, and less autonomous with negative coordinates.

viii Different industries were tested as references to ensure this result was not dependent on the choice of finance and administrative services as a refence category. Results remained unchanged.
} 


\section{Appendix}

\section{Appendix I: Descriptive statistics on indicators of temporal autonomy}

\begin{tabular}{|c|c|c|}
\hline Variables & Modalities & Total \\
\hline $\mathrm{N}$ & & 8086 \\
\hline \multicolumn{3}{|c|}{ Dim 1: Control and adaptability of work time } \\
\hline \multirow[t]{4}{*}{ Choice of work hours } & Employee chooses freely & 13.8 \\
\hline & Employer and employee choose jointly & 22.1 \\
\hline & Employer chooses hours & 64.0 \\
\hline & & 100 \\
\hline \multirow[t]{3}{*}{ Wishes to work more hours } & Yes & 26.7 \\
\hline & No & 73.3 \\
\hline & & 100 \\
\hline \multirow[t]{5}{*}{ Wishes to change hours } & Change work hours & 24.6 \\
\hline & $\begin{array}{l}\text { Change government agencies or social services } \\
\text { hours }\end{array}$ & 25.3 \\
\hline & Change other hours & 21.1 \\
\hline & Not answered* & 28.9 \\
\hline & & 100 \\
\hline \multirow{3}{*}{$\begin{array}{l}\text { Knows schedule a day } \\
\text { ahead }\end{array}$} & Yes & 90.5 \\
\hline & No & 9.5 \\
\hline & & 100 \\
\hline \multirow{3}{*}{$\begin{array}{l}\text { Knows schedule a week } \\
\text { ahead }\end{array}$} & Yes & 83.8 \\
\hline & No & 16.2 \\
\hline & & 100 \\
\hline \multirow{3}{*}{$\begin{array}{l}\text { Knows schedule a month } \\
\text { ahead }\end{array}$} & Yes & 71.8 \\
\hline & No & 28.2 \\
\hline & & 100 \\
\hline \multirow{4}{*}{ Free to schedule breaks } & Dim 2: Control over time off & \\
\hline & Yes & 70.3 \\
\hline & No & 29.7 \\
\hline & & 100 \\
\hline \multirow{5}{*}{$\begin{array}{l}\text { Free to leave work during } \\
\text { work hours }\end{array}$} & Without difficulty & 24.7 \\
\hline & Arrangement with boss or colleagues & 47.2 \\
\hline & Loss of pay or vacation day & 19.9 \\
\hline & Impossible to leave & 8.2 \\
\hline & & 100 \\
\hline \multirow[t]{4}{*}{ Length of lunch break } & No lunch break & 12.3 \\
\hline & Less than one hour & 65.7 \\
\hline & More than one hour & 21.9 \\
\hline & & 100 \\
\hline \multirow[t]{3}{*}{ Choice of vacation dates } & Free vacation dates & 61.1 \\
\hline & Imposed vacation dates & 38.9 \\
\hline & & 100 \\
\hline \multirow{4}{*}{$\begin{array}{l}\text { Submitted to presence } \\
\text { control }\end{array}$} & Dim 3: Autonomy in work organization & \\
\hline & Yes & 33.4 \\
\hline & No & 66.6 \\
\hline & & 100 \\
\hline \multirow[t]{4}{*}{ Workplace } & Works at home & 6.9 \\
\hline & Works at a regular location & 80.8 \\
\hline & Workplace varies & 12.2 \\
\hline & & 100 \\
\hline \multirow[t]{5}{*}{ Brings work home } & Regularly & 9.4 \\
\hline & Occasionally & 14.9 \\
\hline & Never & 65.9 \\
\hline & Cannot bring work home & 9.8 \\
\hline & & 100 \\
\hline
\end{tabular}

Source: French Time-Use Survey 2010

Note: Means are weighted with a standardized individual weighting variable available in the database. 


\section{Appendix II - MCA}

Figure A: Modified inertia rates for the first 8 dimensions

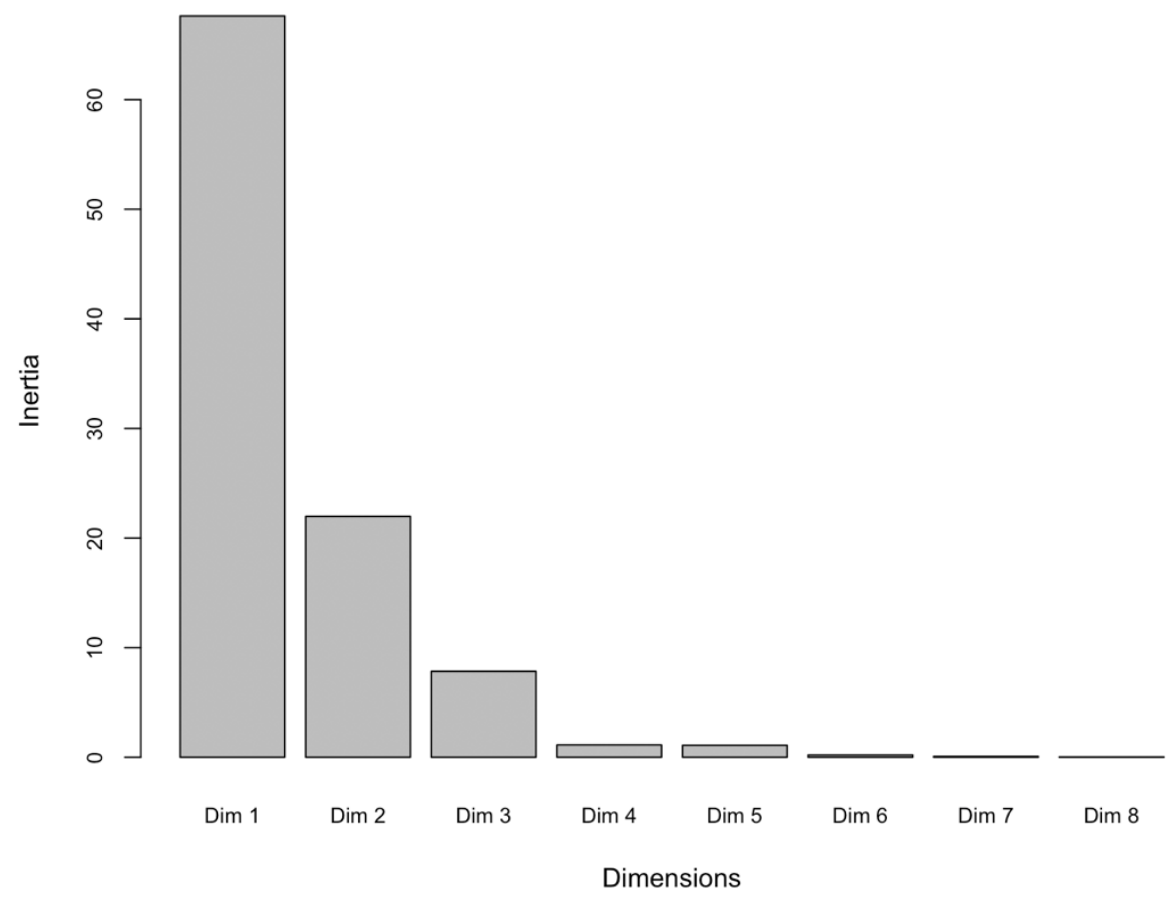

Figure B: Cloud of active individuals on the first plan (1-2)

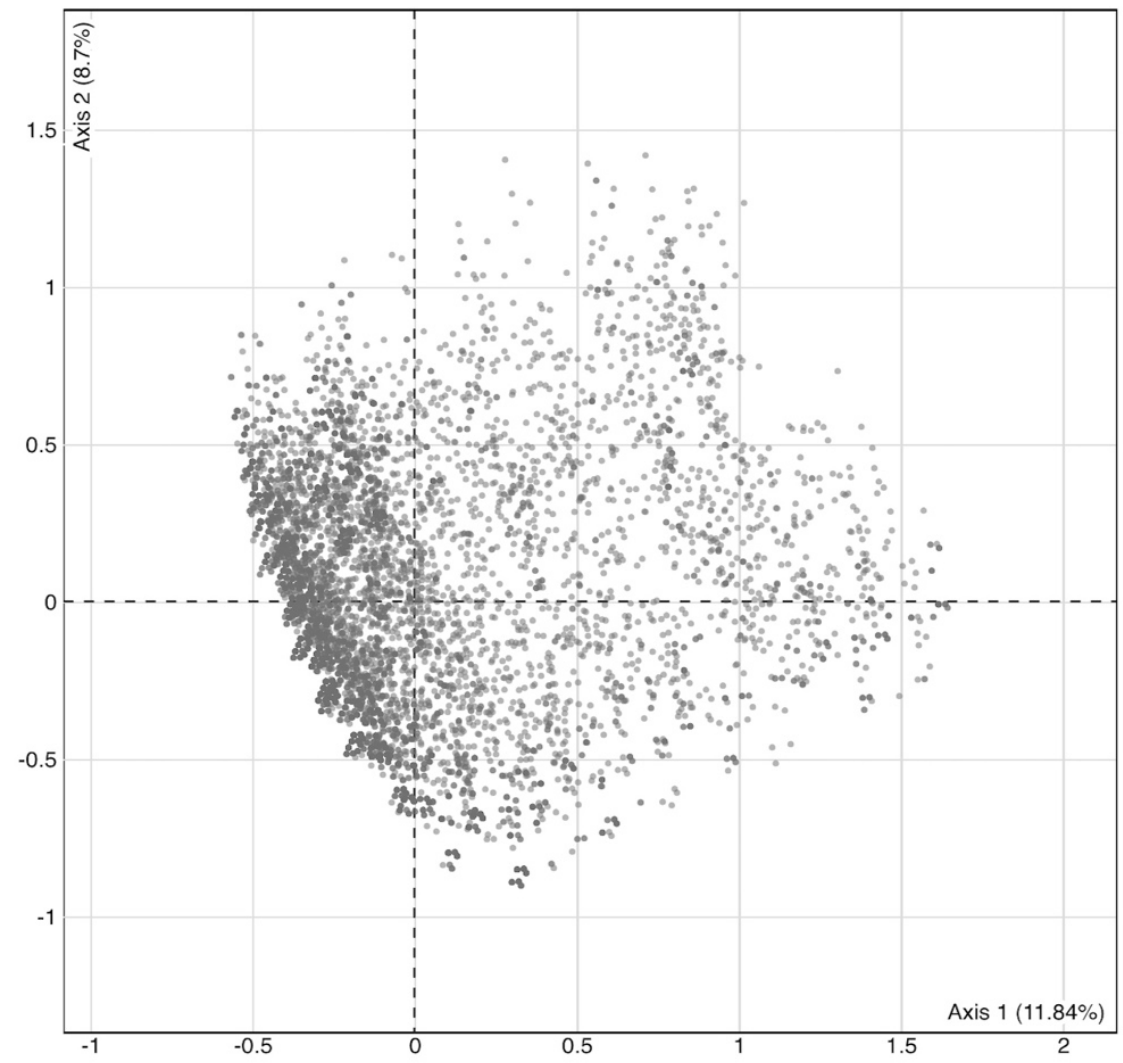


Figure C: Cloud of active individuals on the second plan (1-3)

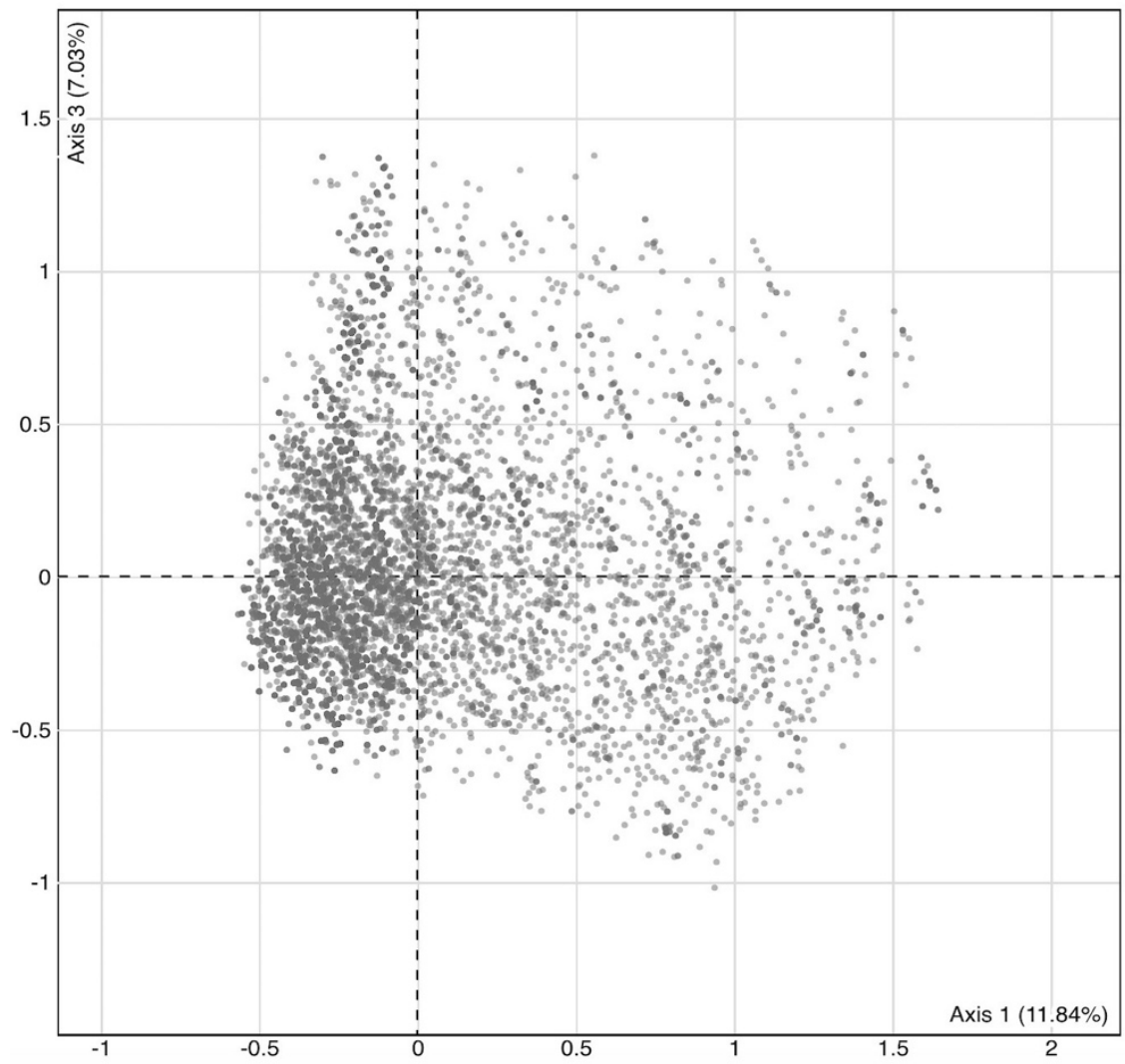

Table A - Coefficient correlations between coordinates and estimates from the test MCA and final MCA

\begin{tabular}{llccc}
\hline & & $\begin{array}{c}\text { Test 1: without "length } \\
\text { of lunch break", "wish } \\
\text { to change hours" and } \\
\text { "wish to work more" }\end{array}$ & $\begin{array}{c}\text { Test 2: without } \\
\text { "unpredictability of } \\
\text { hours for the next day" }\end{array}$ & $\begin{array}{c}\text { Test 3: without } \\
\text { "working from home" } \\
\text { and "bringing work } \\
\text { home regularly" }\end{array}$ \\
\hline \multirow{3}{*}{ Coordinates } & Axis 1 & 1.00 & 0,92 & 0,99 \\
& Axis 2 & 0.97 & 0,94 & 1,00 \\
Exis 3 & 0.99 & 0,97 & 0,75 \\
\hline \multirow{3}{*}{ Estimates } & Model 1 & 1.00 & 0,94 & 0,97 \\
& Model 2 & 1.00 & 0,95 & 0,98 \\
& Model 3 & 0.99 & 0,93 & 1,00 \\
& Model 4 & 0.99 & 0,91 & 1,00 \\
& Model 5 & 1.00 & 0,98 & 0,87 \\
\end{tabular}

Source: French Time-Use Survey 2010 


\section{Table B - Coordinates and contributions of all 13 indicators for the first 3 dimensions}

\begin{tabular}{|c|c|c|c|c|c|c|c|}
\hline & & \multicolumn{2}{|c|}{ Dimension 1} & \multicolumn{2}{|c|}{ Dimension 2} & \multicolumn{2}{|c|}{ Dimension 3} \\
\hline & Modalities & Coord. & Contrib. & Coord. & Contrib. & Coord. & Contrib. \\
\hline \multirow{3}{*}{$\begin{array}{l}\text { Choice of work } \\
\text { hours }\end{array}$} & Employee chooses freely & 1.39 & 10.24 & -0.77 & 4.33 & 0.75 & 5.09 \\
\hline & Employer and employee choose jointly & 0.15 & 0.19 & -0.51 & 2.96 & -0.75 & 8.15 \\
\hline & Employer chooses hours & -0.35 & 3.05 & 0.34 & 3.92 & 0.10 & 0.40 \\
\hline \multirow{2}{*}{$\begin{array}{l}\text { Knows } \\
\text { schedule a day } \\
\text { ahead }\end{array}$} & Yes & -0.23 & 1.86 & -0.09 & 0.40 & 0.06 & 0.24 \\
\hline & No & 2.21 & 17.78 & 0.87 & 3.78 & -0.61 & 2.26 \\
\hline \multirow{2}{*}{$\begin{array}{l}\text { Knows } \\
\text { schedule a } \\
\text { week ahead }\end{array}$} & Yes & -0.35 & 3.86 & -0.16 & 1.08 & 0.10 & 0.52 \\
\hline & No & 1.79 & 19.94 & 0.81 & 5.60 & -0.51 & 2.68 \\
\hline \multirow{2}{*}{$\begin{array}{l}\text { Knows } \\
\text { schedule a } \\
\text { month ahead }\end{array}$} & Yes & -0.46 & 5.79 & -0.22 & 1.84 & 0.10 & 0.50 \\
\hline & No & 1.17 & 14.74 & 0.56 & 4.68 & -0.27 & 1.28 \\
\hline \multirow{2}{*}{$\begin{array}{l}\text { Wishes to work } \\
\text { more }\end{array}$} & Wish to work more & -0.08 & 0.06 & 0.39 & 2.13 & -0.29 & 1.45 \\
\hline & No wish to work more & 0.03 & 0.02 & -0.14 & 0.78 & 0.11 & 0.53 \\
\hline \multirow{4}{*}{$\begin{array}{l}\text { Wishes to } \\
\text { change hours }\end{array}$} & Change work hours & -0.16 & 0.23 & 0.42 & 2.24 & -0.14 & 0.32 \\
\hline & $\begin{array}{l}\text { Change government agencies or social services } \\
\text { hours }\end{array}$ & 0.12 & 0.15 & -0.17 & 0.40 & -0.20 & 0.62 \\
\hline & Change other hours & 0.08 & 0.06 & -0.11 & 0.14 & 0.10 & 0.13 \\
\hline & Not answered & -0.04 & 0.01 & -0.12 & 0.22 & 0.22 & 0.90 \\
\hline \multirow{4}{*}{$\begin{array}{l}\text { Free to leave } \\
\text { work during } \\
\text { work hours }\end{array}$} & Without difficulty & 0.69 & 4.56 & -0.83 & 8.83 & 0.39 & 2.46 \\
\hline & Arrangements with boss or colleagues & -0.23 & 0.92 & 0.17 & 0.69 & -0.18 & 0.94 \\
\hline & Loss of pay or vacation day & -0.26 & 0.53 & 0.07 & 0.05 & -0.55 & 3.97 \\
\hline & Impossible to leave & -0.15 & 0.07 & 1.37 & 8.01 & 1.18 & 7.36 \\
\hline \multirow{2}{*}{$\begin{array}{l}\text { Free to } \\
\text { schedule breaks }\end{array}$} & Yes & 0.18 & 0.86 & -0.39 & 5.64 & -0.07 & 0.26 \\
\hline & No & -0.42 & 2.04 & 0.93 & 13.36 & 0.18 & 0.61 \\
\hline \multirow{2}{*}{$\begin{array}{l}\text { Choice of } \\
\text { vacation dates }\end{array}$} & Free vacation dates & 0.06 & 0.08 & -0.37 & 4.36 & -0.14 & 0.74 \\
\hline & Imposed vacation dates & -0.09 & 0.12 & 0.58 & 6.86 & 0.22 & 1.17 \\
\hline \multirow{3}{*}{$\begin{array}{l}\text { Length of lunch } \\
\text { break }\end{array}$} & No lunch break & -0.22 & 0.23 & 0.75 & 3.62 & 0.32 & 0.81 \\
\hline & Less than one hour & 0.05 & 0.07 & -0.06 & 0.11 & -0.08 & 0.28 \\
\hline & More than one hour & -0.04 & 0.01 & -0.25 & 0.74 & 0.06 & 0.06 \\
\hline \multirow{2}{*}{$\begin{array}{l}\text { Submitted to } \\
\text { presence } \\
\text { control }\end{array}$} & Yes & -0.30 & 1.15 & 0.45 & 3.54 & -0.57 & 6.92 \\
\hline & No & 0.15 & 0.58 & -0.23 & 1.77 & 0.28 & 3.47 \\
\hline \multirow[t]{3}{*}{ Workplace } & Works at home & 0.42 & 0.46 & 0.20 & 0.15 & 2.23 & 22.28 \\
\hline & Works at a regular location & -0.17 & 0.94 & -0.08 & 0.26 & -0.19 & 1.93 \\
\hline & Workplace varies & 0.91 & 3.88 & 0.41 & 1.06 & 0.00 & 0.00 \\
\hline \multirow{4}{*}{$\begin{array}{l}\text { Brings work } \\
\text { home }\end{array}$} & Regularly & 0.82 & 2.43 & 0.20 & 0.20 & 1.31 & 10.37 \\
\hline & Occasionally & 0.54 & 1.68 & -0.79 & 4.86 & -0.34 & 1.12 \\
\hline & Never & -0.24 & 1.40 & 0.08 & 0.21 & -0.27 & 3.04 \\
\hline & Cannot bring work home & -0.03 & 0.00 & 0.48 & 1.18 & 1.07 & 7.17 \\
\hline
\end{tabular}

Source: French Time-Use Survey 2010 


\section{Appendix III - OLS estimates for the 24-categories occupational scheme}

\begin{tabular}{|c|c|c|c|c|}
\hline Variables & Modalities & Dim 1 & $\operatorname{Dim} 2$ & $\operatorname{Dim} 3$ \\
\hline \multirow{47}{*}{$\begin{array}{l}\text { Occupation } \\
\text { (PCS) }\end{array}$} & \multirow[t]{2}{*}{ Liberal professions (31) } & $0.58 * * *$ & -0.07 & 0.13 \\
\hline & & $(0.18)$ & $(0.15)$ & $(0.34)$ \\
\hline & \multirow[t]{2}{*}{ Public service executives (33) } & $0.37 * * *$ & $0.22 * *$ & $-0.20 * *$ \\
\hline & & $(0.11)$ & $(0.10)$ & $(0.09)$ \\
\hline & \multirow[t]{2}{*}{ 2ndary and high education teachers (34) } & $0.45^{* * *}$ & $-0.45 * * *$ & $0.70 * * *$ \\
\hline & & $(0.11)$ & $(0.10)$ & $(0.10)$ \\
\hline & \multirow[t]{2}{*}{ Information, art and entertainment occupations (35) } & $0.56^{* * *}$ & $-0.36 * *$ & $0.55^{* * *}$ \\
\hline & & $(0.16)$ & $(0.15)$ & $(0.16)$ \\
\hline & \multirow[t]{2}{*}{ Administrative and commercial managers (37) } & $0.59 * * *$ & $0.32 * * *$ & $0.18^{* *}$ \\
\hline & & $(0.08)$ & $(0.07)$ & $(0.07)$ \\
\hline & \multirow[t]{2}{*}{ Technical managers and engineers (38) } & $0.60 * * *$ & $0.26^{* * *}$ & -0.06 \\
\hline & & $(0.09)$ & $(0.07)$ & $(0.07)$ \\
\hline & \multirow[t]{2}{*}{ Kindergarten or primary education teachers (42) } & $0.17 * *$ & $-0.50 * * *$ & $0.52 * * *$ \\
\hline & & $(0.09)$ & $(0.10)$ & $(0.09)$ \\
\hline & \multirow[t]{2}{*}{ Health and social intermediary occupations (43) } & 0.12 & $-0.37 * * *$ & $0.11 *$ \\
\hline & & $(0.08)$ & $(0.08)$ & $(0.07)$ \\
\hline & \multirow[t]{2}{*}{ Public service intermediary occupations (45) } & $0.24 * *$ & -0.01 & $-0.44 * * *$ \\
\hline & & $(0.11)$ & $(0.10)$ & $(0.08)$ \\
\hline & \multirow[t]{2}{*}{ Private sector admin. intermediary occupations (46) } & $0.50 * * *$ & 0.09 & 0.01 \\
\hline & & $(0.07)$ & $(0.06)$ & $(0.06)$ \\
\hline & \multirow[t]{2}{*}{ Technicians (47) } & $0.17 * *$ & -0.02 & $-0.17 * * *$ \\
\hline & & $(0.08)$ & $(0.07)$ & $(0.06)$ \\
\hline & \multirow[t]{2}{*}{ Foremen (48) } & $0.48 * * *$ & -0.15 & $-0.14 *$ \\
\hline & & $(0.13)$ & $(0.09)$ & $(0.08)$ \\
\hline & \multirow[t]{2}{*}{ Public service clerks (52) } & 0.03 & $-0.33 * * *$ & -0.10 \\
\hline & & $(0.07)$ & $(0.07)$ & $(0.06)$ \\
\hline & \multirow[t]{2}{*}{ Surveillance agents (53) } & 0.03 & $-0.75 * * *$ & $0.15^{*}$ \\
\hline & & $(0.10)$ & $(0.11)$ & $(0.08)$ \\
\hline & Private sector administrative clerks (54) & $\operatorname{Ref}$ & $\operatorname{Ref}$ & Ref \\
\hline & \multirow[t]{2}{*}{ Retail workers (55) } & -0.06 & $-0.42 * * *$ & -0.07 \\
\hline & & $(0.07)$ & $(0.08)$ & $(0.07)$ \\
\hline & \multirow[t]{2}{*}{ Care workers (56) } & 0.11 & $-0.60 * * *$ & $0.34 * * *$ \\
\hline & & $(0.07)$ & $(0.08)$ & $(0.08)$ \\
\hline & \multirow[t]{2}{*}{ Skilled industrial labor (62) } & $-0.23 * * *$ & $-0.57 * * *$ & $-0.11^{*}$ \\
\hline & & $(0.07)$ & $(0.07)$ & $(0.06)$ \\
\hline & \multirow{2}{*}{ Skilled craft labor (63) } & -0.08 & $-0.33 * * *$ & -0.01 \\
\hline & & $(0.07)$ & $(0.07)$ & $(0.06)$ \\
\hline & \multirow[t]{2}{*}{ Drivers (64) } & $0.79 * * *$ & $-1.02 * * *$ & $-0.16^{*}$ \\
\hline & & $(0.12)$ & $(0.11)$ & $(0.09)$ \\
\hline & \multirow[t]{2}{*}{ Handling, storing and transport labor (65) } & $-0.17 *$ & $-0.53 * * *$ & 0.01 \\
\hline & & $(0.09)$ & $(0.11)$ & $(0.09)$ \\
\hline & Unskilled industrial labor (67) & $-0.15^{*}$ & $-0.52 * * *$ & -0.11 \\
\hline & & $(0.09)$ & $(0.08)$ & $(0.08)$ \\
\hline & Unskilled craft labor (68) & $0.04)$ & $-0.39 * * *$ & -0.09 \\
\hline & & $(0.09)$ & $(0.09)$ & $(0.08)$ \\
\hline & Unskilled farm labor (69) & 0.24 & $-0.52 * * *$ & 0.20 \\
\hline & & $(0.21)$ & $(0.15)$ & $(0.15)$ \\
\hline Observations & & 8086 & 8086 & 8086 \\
\hline $\mathrm{R}^{2}$ & & 0.2 & 0.28 & 0.28 \\
\hline Adjusted $\mathrm{R}^{2}$ & & 0.19 & 0.27 & 0.27 \\
\hline
\end{tabular}

Source: French Time-Use Survey 2010

Note: $\mathrm{p}<0,1: * ; \mathrm{p}<0,05: * * ; \mathrm{p}<0,01: * * *$. OLS models are weighted with a standardized individual weighting variable available in the database. Only occupations are displayed here but all previous variables were included in the models (gender, education, income, industry, size of establishment, sector of employment, type of contract, seniority, age, family situation, presence and age of children, size of the urban unit and level of education of both parents). 